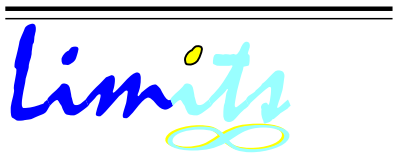

J. Math. and Its Appl.

ISSN : 1829-605X

Vol. 2, No. 1, May. 2005, 47-59

\title{
Analisis Pengendalian Kualitas Multivariate Air Minum (Studi Kasus di PDAM Gresik)
}

\author{
Nuri Wahyuningsih, Dwi Pusdikarta
}

Jurusan Matematika

Institut Teknologi Sepuluh Nopember, Surabaya

\begin{abstract}
Abstrak
Air merupakan kebutuhan pokok kehidupan, masalah kualitas air merupakan masalah yang perlu perhatian serius. Penelitian ini bertujuan untuk mengetahui variabel apa saja yang berpengaruh terhadap kualitas air produksi PDAM Gresik dan apakah variabel-variabel tersebut sudah terkendali secara statistik. Dengan analisis komponen utama dan analisis faktor didapatkan enam variabel yang berpengaruh terhadap kualitas air, yaitu TDS, Kesadahan, Kekeruhan, Timbal (Pb), Besi (Fe) dan Suhu. Dengan pengendalian kualitas multivariate, diantara variabel yang berpengaruh TDS, Kesadahan dan Suhu adalah variabel kualitas air produksi PDAM Gresik yang belum terkendali secara statistik.
\end{abstract}

Kata kunci: Analisa Komponen Utama, Analisa Faktor, Pengendalian Kualitas Multivariat

\section{Pendahuluan}

Di PDAM terdapat instalasi khusus untuk mengolah air baku menjadi air bersih yang siap di distribusikan kepada mayarakat, penelitian ini lebih difokuskan pada Instalasi Penjernihan Air minum (IPA) PDAM Gresik. Air minum yang dihasilkan, harus diperiksa kualitasnya sesuai dengan SK Menteri Kesehatan Republik Indonesia no 416/MENKES/PER/IX/1990. 
Dari hasil penelitian Ulin Yudhawati yang berjudul Analisis Multivariate Pada Proses Pengolahan Air Minum Instalansi Penjernihan II di PDAM Kotamadya Surabaya [5], penelitian ini dilakukan untuk melihat apakah PDAM Gresik mempunyai karakteristik yang sama dengan PDAM Surabaya. Perumusan masalah dalam penelitian ini adalah variabel apa sajakah yang berpengaruh terhadap kualitas air produksi PDAM Gresik. Apakah variabel kualitas air tersebut sudah terkendali secara statistik. Penelitian ini dilakukan dengan mengambil data dari laboratorium IPA PDAM Gresik dan pengamatan dilakukan pada bulan JanuariMaret 2005.

\section{Analisa Pengendalian Multivariate}

Teori-teori yang mendasari penelitian ini adalah analisis komponen utama, analisis faktor dan yang berkaitan dengan pengendalian kualitas multivariate.

\subsection{Analisis Komponen Utama}

Analisis komponen utama bertujuan untuk mereduksi sejumlah besar variabel yang saling berkorelasi ke dalam sejumlah kecil komponen yang saling bebas (independen)[1]. Misal vektor random $X^{\prime}=\left[X_{1}, X_{2}, \cdots, X_{p}\right]$ mengikuti distribusi normal multivariate tertentu dengan vektor mean $\mu^{\prime}=\left[\mu_{1}, \mu_{2}, \cdots, \mu_{p}\right]$ dan matrik varian kovarians $\sum$. Dari persamaan

$$
\left|\sum-\lambda I\right|=0
$$

akan diperoleh nilai eigen yaitu $\lambda_{1} \geq \lambda_{2} \geq \cdots \lambda_{p} \geq 0$. Pandang kombinasi linier :

$$
\begin{aligned}
& Y_{1}=e_{1}^{\prime} X=e_{11} X_{1}+e_{12} X_{2}+\cdots+e_{1 p} X_{p} \\
& Y_{2}=e_{2}^{\prime} X=e_{21} X_{1}+e_{22} X_{2}+\cdots+e_{2 p} X_{p} \\
& \cdots \\
& Y_{p}=e_{p}^{\prime} X=e_{p 1} X_{1}+e_{p 2} X_{2}+\cdots+e_{p p} X_{p}
\end{aligned}
$$

dengan : $\operatorname{var}\left(Y_{i}\right)=e_{i}^{\prime} \sum e_{i}$ dan $\operatorname{cov}\left(Y_{i}, Y_{k}\right)=e_{i}^{\prime} \sum e_{k}$, dimana $e$ adalah vektor ciri atau matrik transformasi yang mengubah variabel $X$ menjadi variabel $Y$ yang disebut komponen utama dan $i, k=1,2, p$.

Secara umum komponen utama ke- $i$ adalah kombinasi linear $e_{i} X$ sedemikian hingga $\operatorname{Var}\left(e_{i}^{\prime} X\right)$ maksimum bila $e_{i}^{\prime} e_{i}=1$ dan $\operatorname{Kov}\left(e_{i}^{\prime} X, e_{k}^{\prime} X\right)=0$ untuk $k<i$. Total keragaman data yang diterangkan oleh setiap komponen utama merupakan 
proporsi nilai eigen komponen tersebut terhadap jumlahan nilai eigen atau trace $\sum$, dapat dijelaskan sebagai berikut :

$$
\sum_{i=1}^{p} \operatorname{Var}\left(X_{i}\right)=\operatorname{tr}\left(\sum\right)=\lambda_{1}+\lambda_{2}+\cdots+\lambda_{p}=\sum_{i=1}^{p} \operatorname{Var}\left(Y_{i}\right)
$$

Sedangkan prosentase keragaman total yang dapat diterangkan oleh komponen utama ke- $i$ adalah sebagai berikut :

$$
\frac{\lambda_{i}}{\sum_{i=1}^{p} \lambda_{i}} \times 100 \%, \quad \text { untuk } \quad i=1,2, \cdots, p
$$

Apabila komponen utama yang di ambil adalah $q(q<p)$, maka prosentase keragaman total yang dapat diterangkan oleh $q$ komponen utama secara bersamaan adalah :

$$
\frac{\lambda_{1}+\lambda_{2}+\cdots+\lambda_{q}}{\sum_{i=1}^{p} \lambda_{i}} \times 100 \%
$$

Matrik varian kovarians $\sum$ digunakan apabila unit pengukuran satuan setiap variabel yang diamati sama dan apabila satuan pengukuran berbeda variabel tersebut perlu distandarkan. Variabel terstandarisasi $(Z)$ diperoleh dengan jalan transformasi variabel asal $(X)$ dengan cara

$$
Z=\left(V^{\frac{1}{2}}\right)^{-1}(X-\mu)
$$

dengan $V^{\frac{1}{2}}$ adalah elemen diagonal utama pada matrik standar deviasi.

\subsection{Analisis Faktor}

Tujuan utama dari analisis faktor adalah untuk menggambarkan hubungan keragaman sejumlah variabel asal yang independen sehingga bisa dibuat kumpulan variabel yang lebih sedikit dari jumlah variabel awal berdasarkan korelasi antar variabel, dimana dalam suatu kelompok variabel mempunyai hubungan yang sangat kuat, tetapi terhadap variabel dalam kelompok lain mempunyai hubungan yang relatif kecil. Analisis faktor dapat digambarkan sebagai perluasan dari analisis komponen utama[1].

Sebelum dilakukan analisis faktor, dilakukan uji Kaiser Mayer Olkin (KMO). Dari uji ini akan dapat dinyatakan, bahwa sampel yang ada sudah mencukupi kelayakan untuk diolah dengan metode analisis faktor.

$$
K M O=\frac{\sum_{i=1}^{p} \sum_{j=1}^{p} r_{i j}^{2}}{\sum_{i=1}^{p} \sum_{j=1}^{p} r_{i j}^{2}+\sum_{i=1}^{p} \sum_{j=1}^{p} a_{i j}^{2}}, \quad i, j=1,2, \cdots, p
$$


dengan :

$r_{i j}$ : koefisien korelasi antara variabel $i$ dan $j$

$a_{i j}$ : koefisien korelasi parsial antara variabel $i$ dan $j$

Karakteristik nilai KMO sebesar $90 \%$ adalah sangat bagus, $80 \%$ bagus, $70 \%$ cukup, $60 \%$ kurang, 50\% jelek dan dibawah 50\% tidak dapat diterima atau dikatakan analisis faktor tidak sesuai untuk variabel-variabel tersebut dan hasilnya akan kurang bermanfaat[4].

Vektor random $X$ dengan $p$ komponen mempunyai vektor rataan $\mu$ dan matrik varian kovarians $\sum$ secara linear bergantung pada sejumlah kecil variabel random yang teramati yaitu $F_{1}, F_{2}, \cdots, F_{q}$ yang disebut common factor dan penyimpangan tambahan $\varepsilon_{1}, \varepsilon_{2}, \cdots, \varepsilon_{p}$ yang disebut residual (error) atau specific factors. Model faktor tersebut

$$
\begin{aligned}
X_{1}-\mu_{1} & =l_{11} F_{1}+l_{12} F_{2}+\cdots+l_{1 m} F_{m}+\varepsilon_{1} \\
X_{2}-\mu_{2} & =l_{21} F_{1}+l_{12} F_{2}+\cdots+l_{2 m} F_{m}+\varepsilon_{2} \\
\cdots & \\
X_{p}-\mu_{p}= & l_{p 1} F_{1}+l_{p 2} F_{2}+\cdots+l_{p m} F_{m}+\varepsilon_{p}
\end{aligned}
$$

atau dalam bentuk matrik dituliskan :

$$
X_{(p \times 1)}-\mu_{(p \times 1)}=L_{(p \times m)} F_{(m \times 1)}+\varepsilon_{(p \times 1)}
$$

dengan :

$i=1,2, \cdots, p$ dan $j=1,2, \cdots, m$

$X_{i}=$ respons ke- $i$

$\mu_{i}=$ rata-rata variabel ke- $i$

$\varepsilon_{i}=$ residual ke- $i$

$F_{j}=$ common faktor ke- $j$

$l_{i j}=$ faktor loading variabel ke- $i$ pada faktor ke- $j=\sqrt{\lambda_{j} e_{j i}}$

Faktor pertama adalah faktor yang mempunyai eigen value paling besar sehingga variabel dari faktor pertama yang diprioritaskan untuk dikendalikan terlebih dahulu. Agar identifikasi anggota variabel dalam faktor lebih mudah, digunakan rotasi orthogonal karena rotasi varimax memaksimumkan jumlah varians semua faktor. 


\subsection{Peta Kendali Hotelling $T^{2}$}

Peta Kendali Hotelling $T^{2}$ digunakan untuk sejumlah karakteristik yang saling berhubungan[2]. Dalam menggunakan peta kendali yang independen, proses dapat dianggap terkendali hanya apabila mean sampel $\bar{x}_{1}, \bar{x}_{2}, \cdots, \bar{x}_{p}$ yang diteliti jatuh dalam kendali masing-masing. Jika $p$ karakteristik yang independen bagi suatu produk dan bagi masing-masing karakteristik dibuat grafik $\bar{x}$ dengan $P$ (kesalahan tipe $I)=\alpha$, maka probabilitas kesalahan tipe $I$ yang benar bagi prosedur pengendalian secara bersama adalah :

$$
\alpha^{\prime}=1-(1-\alpha)^{p}
$$

Dan probabilitas bahwa semua p mean akan bersama-sama jatuh di dalam batas pengendali masing-masing apabila proses terkendali adalah:

$$
P(\text { semua } p \text { mean jatuh terkendali })=(1-\alpha)^{p}
$$

Dari nilai batas pengendali $T^{2}$ Hotelling dapat dihitung sebagai berikut :

$$
T^{2}=n(\bar{x}-\mu)^{\prime} S^{-1}(\bar{x}-\mu)
$$

dengan $\bar{x}=\left(\bar{x}_{1}, \bar{x}_{2}, \cdots, \bar{x}_{p}\right.$ dan $\mu=\left(\mu_{1}, \mu_{2}, \cdots, \mu_{p}\right)$ adalah vektor nilai nominal bagi tiap karakteristik kualitas. $S$ adalah matrik kovarians $p$ karakteristik kualitas $x_{1}, x_{2}, \cdots, x_{p}$. Jika $T^{2}>T_{\alpha, p, n-1}^{2}$, maka paling sedikit satu dari karakteristik kualitas ini tidak terkendali.

Batas Kendali Atas (BKA) untuk peta kendali ini adalah :

$$
B K A=T_{\alpha, p, n-1}^{2}=\frac{p(n-1)}{n-1} F_{\alpha, p, n-1}
$$

Dengan $p$ menyatakan banyak karakteristik kualitas dan $n$ menyatakan ukuran sampel Batas Kendali Bawah $(B K B)$ akan bernilai nol jika nilai yang didapat kurang dari nol.

$$
B K B=0
$$

\subsection{Analisa Kemampuan Proses Multivariate}

Analisa kapabilitas proses bertujuan untuk menganalisa variabilitas terhadap spesifikasi suatu variabel yang selanjutnya dapat digunakan untuk mengurangi variabilitas tersebut. Jika asumsi multinormal telah terpenuhi maka bentuk dasar kapabilitas proses adalah sebagai berikut :

$$
W=(X-\underline{\xi})^{\prime} V_{0}^{-1}(X-\underline{\xi})
$$


Statistik $W$ berdistribusi Chi-square dengan derajat bebas $p$. Daerah spesifikasi proses sebenarnya mempunyai bentuk $W \leq \chi_{p ; 0,9973}^{2}=C p^{2}$ mempunyai probabilitas harapan produk dalam keadaan cacat adalah sebesar 0,27\%[3].

Bentuk daerah spesifikasi yang telah dimodifikasi adalah $R^{*}$ sebagai volume terbesar ellipsoid dengan membangkitkan matrik varian kovarians $\left(V_{0}^{-1}\right)$ yang merupakan daerah spesifikasi sesungguhnya $R$. Jika daerah proses yang diijinkan $(X-\underline{\xi})^{\prime} V_{0}^{-1}(X-\underline{\xi}) \leq K^{2}$ maka bentuk indeks kapabilitas prosesnya adalah :

$$
C p^{*}=\frac{\text { volume } R^{*}}{\text { volume }(X-\underline{\xi})^{\prime} V_{0}^{-1}(X-\underline{\xi}) \leq \chi_{p ; 0,9973}^{2}}=\left(\frac{K^{2}}{\chi_{p ; 0,9973}^{2}}\right)^{\frac{p}{2}}
$$

dengan : $\underline{\xi}=\frac{1}{2}(B S A+B S B)$

Secara sederhana persamaan untuk indeks kapabilitas proses $(C p)$ multivariat adalah sebagai berikut :

$$
{ }_{p} C p=\frac{K}{\chi_{p ; 0,9973}^{2}}\left(\frac{(n-1) p}{S}\right)
$$

dengan :

$$
\begin{aligned}
& S=\sum_{j=1}^{n}\left(X_{j}-\bar{X}\right)^{\prime} A^{-1}\left(X_{j}-\bar{X}\right) \\
& A=X_{j}^{\prime} X_{j} \\
& K^{2}=(X-\underline{\xi}) V_{0}^{-1}(X-\underline{\xi})
\end{aligned}
$$

Adapun ketentuan interpretasi dari $C p$ adalah sebagai berikut :

1. Jika $C p=1$, dikatakan proses dalam keadaan cukup baik.

2. Jika $C p>1$, proses dalam keadaan baik.

3. Jika $C p<1$, maka sebaran data pengamatan berada di luar batas spesifikasi.

\subsection{Uji Distribusi Normal Multivariate}

Pengujian Distribusi Normal Multivariate dilakukan untuk asumsi dasar yang harus dipenuhi, dalam analisis peta kendali multivariate dan analisis kemampuan proses multivariat. Jika dilakukan pengamatan terhadap $p$ variabel, maka

$$
f(x)=\frac{1}{(2 \pi)^{\frac{p}{2}}\left|\sum\right|^{\frac{1}{2}}} \exp \left(\frac{-(x-\mu)^{\prime} \sum^{-1}(x-\mu)}{2}\right)
$$

dengan :

$\sum=$ matriks kovarians 
$\mu=$ nilai harapan dari vektor random $X$

Kemultinormalan diuji dengan menghitung jarak kuadrat setiap pengamatan[1] dengan menggunakan plot $\chi^{2}$.

$$
d_{j}^{2}=\left(x_{j}-\bar{x}\right)^{\prime} S^{-1}\left(x_{j}-\bar{x}\right), \quad j=1,2, \cdots, n
$$

dengan :

$x_{j}=$ obyek pengamatan ke- $j$

$n=$ banyak pengamatan

$S^{-1}=$ invers matrik varian kovarians yang berukuran $p \times p$

$P=$ banyak variabel

Hipotesis yang digunakan

$H_{0}$ : Data berdistribusi normal multivariate.

$H_{1}$ : Data tidak berdistribusi normal multivariate.

Statistik Uji

$$
d_{j}^{2}=\left(x_{j}-\bar{x}\right)^{\prime} S^{-1}\left(x_{j}-\bar{x}\right)
$$

$H_{0}$ diterima apabila $50 \%$ berada di bawah $\chi_{(p ; 0,5)}^{2}$ atau $d_{j}^{2} \leq \chi_{(p ; 0,5)}^{2}$

\section{Hasil Penelitian}

Data diambil dari hasil pengujian Laboratorium Instalasi Penjernihan Air (IPA) Legundi pada bulan Januari-Maret 2005. Variabel-variabel yang diamati adalah Warna, TDS, Kesadahan, Kekeruhan, Timbal $(P b)$, Sisa Khlor(sisa $C l)$, $\operatorname{Natrium}(\mathrm{Na})$, Sulfat $\left(\mathrm{SO}^{2-}{ }^{2}\right)$, Besi $(\mathrm{Fe}), \mathrm{pH}$, Suhu dan $\operatorname{Kadmium}(\mathrm{Cd})$

Hasil analisis diskripsi dari variabel teramati dapat dilihat pada Tabel 1. Sedangkan hasil uji KMO dapat dilihat pada Tabel 2. 
Tabel 1: Hasil Analisis Statistik Deskriptif

\begin{tabular}{|l|c|c|c|c|}
\hline & $\mathrm{N}$ & Mean & S. Deviasi & Varian \\
\hline Warna & 72 & 3.8090 & 1.31234 & 1.722 \\
TDS & 72 & 171.0694 & 96.07059 & 9229.558 \\
Kesahana & 72 & 162.6943 & 19.53019 & 381.478 \\
Kekeruhan & 72 & .5657 & .21448 & .046 \\
$\mathrm{~Pb}$ & 72 & .0233 & .01163 & .000 \\
Sisa_Cl & 72 & 1.4364 & 1.00681 & 1.014 \\
$\mathrm{Na}$ & 72 & 3.7919 & 2.09446 & 4.387 \\
$\mathrm{Sulfat}$ & 72 & .2794 & .27558 & .076 \\
Fe & 72 & .0790 & .03367 & .001 \\
$\mathrm{pH}$ & 72 & 7.768 & .13705 & .019 \\
Suhu & 72 & 24.7819 & .84108 & .707 \\
Cd & 72 & 129.606 & 1.76135 & 3.102 \\
Valid N (listwise) & 72 & & & \\
\hline
\end{tabular}

Tabel 2: Hasil Uji KMO dan Bartlett's Test

\begin{tabular}{|l|l|r|}
\hline \multicolumn{2}{|l|}{ Kaiser-Meyer-Olkin Measure of Sampling Adequacy } & .417 \\
\hline Bartlett's Test of Sphericity & Approx. Chi-Square & 81.035 \\
& $\mathrm{df}$ & 66 \\
& Sig & .101 \\
\hline
\end{tabular}

Dari dua belas variabel teramati, dengan data sampel karakteristik kualitas air yang terstandartisasi, dengan menggunakan program SPSS 13.0, berdasarkan KMO and Bartlett's Test pada Tabel 2 sebesar 0,417 dengan signifikansi 0,101, maka variabel tidak dapat dianalisis lebih lanjut. Ini dikarenakan nilai $\mathrm{KMO}$ and Bartlett's Test berada di bawah 0,5 dan signifikansi di atas 0,001 sehingga perlu adanya variabel yang dikeluarkan.

Tabel 3: KMO dan Bartlett's Test Perbaikan

\begin{tabular}{|l|l|r|}
\hline \multicolumn{2}{|c|}{ Kaiser-Meyer-Olkin Measure of Sampling Adequacy } & .633 \\
\hline Bartlett's Test of Sphericity & Approx. Chi-Square & 42.170 \\
& $\mathrm{df}$ & 15 \\
& $\mathrm{Sig}$ & .000 \\
\hline
\end{tabular}

Setelah dilakukan pengeluaran variabel warna, sisa $\mathrm{Cl}, \mathrm{Na}$, Sulfat, $\mathrm{pH}$ dan $C d$ yang memiliki angka paling rendah maka dapat terlihat bahwa nilai KMO and Bartlett's Test pada Tabel 3 sekarang naik menjadi 0,633 dan juga tetap signifikan (angka signifikan adalah di bawah 0,001). Dari Tabel 4, setelah dilakukan Analisis komponen utama ternyata diperoleh 2 komponen utama yang mempunyai nilai eigen lebih besar sama dengan satu $(\lambda=1)$, dengan total keragaman yang dapat diterangkan sebesar 54,094\%. Tetapi karena dari loading awal pada Tabel 5 
terdapat variabel yang sulit untuk dimasukkan ke dalam salah satu faktor maka perlu dilakukan rotasi dengan menggunakan rotasi tegak lurus varimax.

Tabel 4: Hasil Analisa Komponen Utama

\begin{tabular}{|c|c|c|c|c|c|c|c|c|c|}
\hline \multirow{2}{*}{$\begin{array}{c}\text { Kom } \\
\text { ponen }\end{array}$} & \multicolumn{3}{|c|}{$\begin{array}{c}\text { Initial } \\
\text { Eigenvalues }\end{array}$} & \multicolumn{3}{c|}{$\begin{array}{c}\text { Extraction Sums of } \\
\text { Squared Loadings }\end{array}$} & \multicolumn{3}{|c|}{$\begin{array}{c}\text { Rotation Sums of } \\
\text { Squared Loadings }\end{array}$} \\
\cline { 2 - 10 } & Total & Var & Kum & Total & Var & Kum & Total & Var & Kum \\
\hline 1 & 1.93 & 32.19 & 32.19 & 1.93 & 32.19 & 32.19 & 1.64 & 27.25 & 27.25 \\
2 & 1.32 & 21.91 & 54.09 & 1.32 & 21.91 & 54.09 & 1.61 & 26.84 & 54.09 \\
3 & .80 & 13.36 & 67.46 & & & & & & \\
4 & .79 & 13.13 & 80.59 & & & & & & \\
5 & .64 & 10.65 & 91.24 & & & & & & \\
6 & .53 & 8.76 & 100.0 & & & & & & \\
\hline
\end{tabular}

Var: Varian (\%), Kum: Kumulatif (\%)

Tabel 5: Matriks Loading Sebelum Rotasi

\begin{tabular}{|l|c|c|}
\hline \multirow{2}{*}{} & \multicolumn{2}{|c|}{ Komponen } \\
\cline { 2 - 3 } & 1 & 2 \\
\hline Zscore(TDS) & 0.669 & -0.465 \\
Zscore(Kesadahan) & -0.666 & 0.155 \\
Zscore(Kekeruhan) & 0.424 & 0.672 \\
Zscore(Pb) & 0.687 & 0.233 \\
Zscore(Fe) & -0.496 & -0.415 \\
Zscore(Suhu) & -0.375 & 0.629 \\
\hline
\end{tabular}

Tabel 6: Matriks Loading Sesudah Rotasi

\begin{tabular}{|l|c|c|}
\hline \multirow{2}{*}{} & \multicolumn{2}{|c|}{ Komponen } \\
\cline { 2 - 3 } & 1 & 2 \\
\hline Zscore(TDS) & -0.805 & 0.129 \\
Zscore(Kesadahan) & 0.588 & -0.350 \\
Zscore(Kekeruhan) & 0.160 & 0.778 \\
Zscore(Pb) & -0.334 & 0.644 \\
Zscore(Fe) & 0.069 & -0.643 \\
Zscore(Suhu) & 0.707 & 0.194 \\
\hline
\end{tabular}

Dari rotasi seperti yang ditampilkan dalam Tabel 6 diperoleh 2 faktor juga dan pengelompokkan variabel menjadi lebih jelas dan mudah untuk diinterpretasikan.

Berdasarkan hasil rotasi varimax, maka Tabel 6 dapat diinterpretasikan sebagai berikut : 
a. Faktor 1

Variabel TDS, variabel kesadahan dan variabel suhu adalah variabel-variabel yang membentuk faktor 1, dimana faktor 1 mampu menerangkan 32, 185\% keragaman data.

b. Faktor 2

Faktor 2 terdiri dari variabel kekeruhan, variabel $P b$ dan variabel $F e$, mampu menerangkan variabilitas data asal sebesar $21,910 \%$.

Selanjutnya dilakukan uji Distribusi Normal Multivariate, untuk Faktor 1 yang terdiri dari variabel TDS, kesadahan dan suhu menggunakan hipotesa sebagai berikut :

Hipotesis:

$H_{0}$ : Data berdistribusi normal multivariate.

$H_{1}$ : Data tidak berdistribusi normal multivariate.

Dan kriteria penolakan, yaitu apabila $50 \%$ berada di bawah $\chi_{(p ; 0,5)}^{2}$ atau $d_{j}^{2} \leq$ $\chi_{(p ; 0,5)}^{2}$. Setelah dilakukan pengujian dengan menggunakan program makro minitab terlihat dalam Gambar 1 . nilai $d_{j}^{2}$ sebanyak 68 dari 72 data atau $94,444 \%$ data berada di bawah nilai chi square $\chi_{(3 ; 0,5)}^{2}=6,34581$ (lebih dari $\left.50 \% d_{j}^{2} \leq \chi_{(3 ; 0,5)}^{2}\right)$
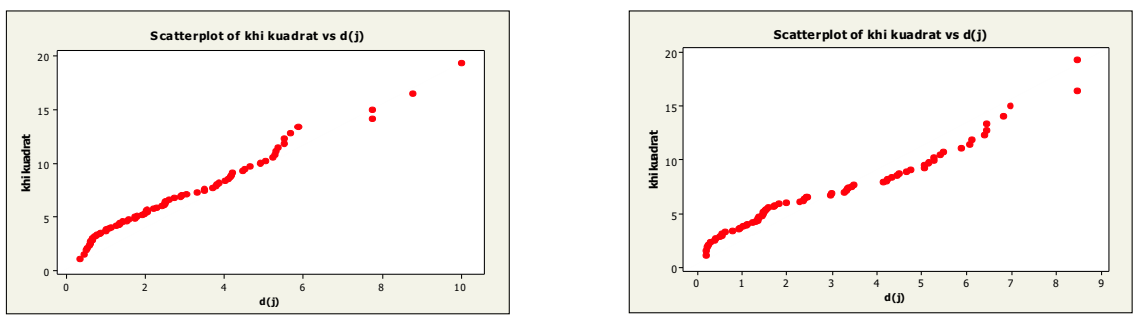

Gambar 1: Plot Uji multinormal faktor 1 Gambar 2: Plot Uji multinormal faktor 2

Faktor 2 yang terdiri dari variabel kekeruhan, $P b$ dan $F e$, Setelah dilakukan pengujian terlihat dalam Gambar 2 nilai $d_{j}^{2}$ sebanyak 65 dari 72 data atau $90,277 \%$ data berada di bawah nilai chi square $\chi_{(3 ; 0,5)}^{2}=6,34581$ (lebih dari $50 \% d_{j}^{2} \leq$ $\left.\chi_{(3 ; 0,5)}^{2}\right)$, sehingga terima $H_{0}$ atau dapat dikatakan data mengikuti pola distribusi normal multivariate

Setelah memenuhi asumsi distribusi normal multivariate, faktor 1 yang terdiri dari variabel TDS, kesadahan dan suhu, dibuat peta kendali multivariate $T^{2}$ Hotelling dan diperoleh batas pengendali atas sebesar $T^{2}=14,29$ dengan $\alpha=0.05$. Dari Gambar 3 tersebut terlihat ada satu titik yang berada di atas 


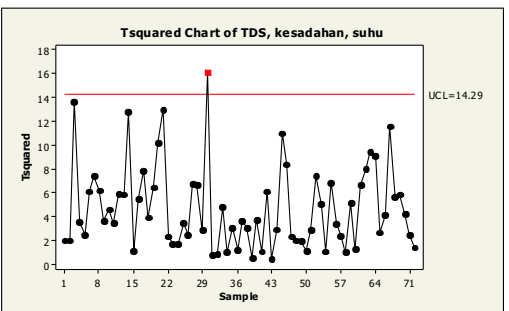

Gambar 3: Peta Kendali $T^{2}$ Hotelling Untuk Faktor 1

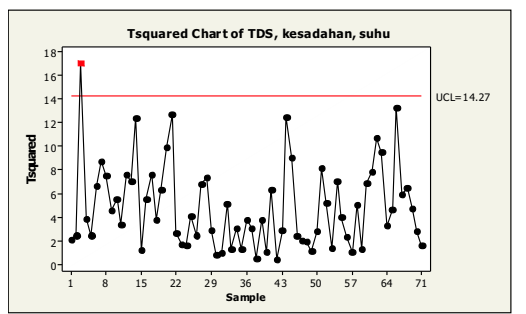

Gambar 4: Peta Kendali $T^{2}$ Hotelling Faktor 1 Penyesuaian ke-1

batas pengendali atas, yaitu titik pengamatan ke-30. Berdasarkan peta kendali $\bar{x}$ dan $S$ ternyata pada variabel TDS, proses koagulan air mengalami keterlambatan yang menyebabkan terjadinya penumpukan endapan. Sedangkan pada variabel kesadahan ikut menumpuknya zat kapur dalam endapan. Langkah selanjutnya adalah dengan membuat peta kandali $T^{2}$ Hotelling penyesuaian dengan $\alpha=0.05$ dan mengeluarkan titik pengamatan ke-30 sehingga diperoleh seperti pada Gambar 4 Ternyata setelah mengalami reduksi data, masih terlihat peta kendali $T^{2}$ Hotelling belum terkendali. Hal ini ditunjukkan dengan keluarnya titik pengamatan ke-3 dari batas pengendali atas $T^{2}=14,27$ dengan $\alpha=0.05$. Setelah diselidiki sekali lagi, variabel TDS dan kesadahan masih belum terkendali. Hal ini dapat dibuktikannya masih ditemukan belum mencairnya koagulan dan zat kapur yang terbentuk. Penambahan floakulan dan pemanasan diharapkan mampu mengurangi terbentuknya koagulan dan zat kapur. Langkah selanjutnya adalah dengan membuat peta kandali $T^{2}$ Hotelling penyesuaian dengan mengeluarkan titik pengamatan ke-3 sehingga diperoleh seperti pada Gambar 5.

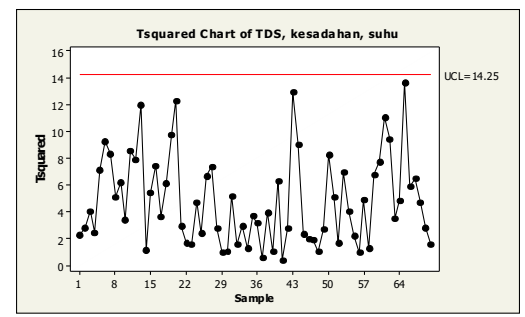

Gambar 5: Peta Kendali $T^{2}$ Hotelling Faktor 1 Penyesuaian ke-2

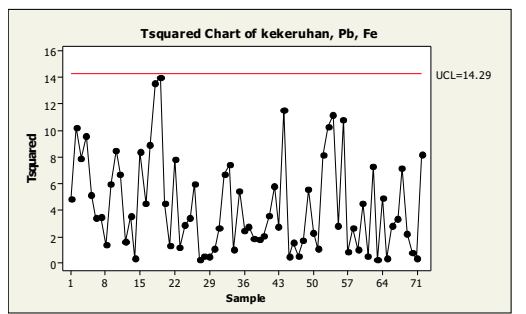

Gambar 6: Peta Kendali T2 Hotelling Untuk Faktor 2

Dari Gambar 5 terlihat pengendalian TDS, kesadahan dan suhu secara bersama sudah terkendali. Hal ini terlihat dengan tidak adanya titik pengamatan yang 
keluar dari batas pengendali atas $T^{2}=14,25$ dengan $\alpha=0.05$.

Dari Gambar 6 terlihat pengendalian kekeruhan, $P b$ dan $F e$ secara bersama sudah terkendali. Hal ini terlihat dengan tidak adanya titik pengamatan yang keluar dari batas pengendali atas $T^{2}=14,29$ dengan nilai statistik uji pada peta kendali di atas $\alpha=0.05$.

Untuk mengetahui kemampuan PDAM dalam mengevaluasi probabilitas karakteristik dari air yang layak disalurkan adalah dengan mengukur indek kemampuan proses $(C p)$. Pengukuran lain dengan menggunakan indek performa proses $(C p k)$.

Untuk data pada analisa faktor 1 akan dilakukan kemampuan proses dengan mengukur nilai $C p$ multivariate dengan menggunakan persamaan 19. Nilai $C p$ faktor 1 diperoleh dengan menggunakan program makro minitab dihasilkan nilai $K^{2}$ dan $S$ dengan $\chi_{3 ; 0.9973}^{2}=14.1563$ sebagai berikut

$$
\begin{aligned}
& K^{2}=177,755 \\
& S=2,00091 \\
& { }_{3} C p=9,71716
\end{aligned}
$$

Karena nilai $C p>1$, maka proses kapabel. Jadi dapat dikatakan bahwa kondisi kemampuan proses yang terjadi pada faktor 1 yang meliputi karakteristik kualitas TDS, kesadahan dan suhu berjalan dengan baik.

Untuk data pada analisa faktor 2 dengan $\chi_{3 ; 0.9973}^{2}=14,1563$ diperoleh sebagai berikut

$$
\begin{aligned}
& K^{2}=116,335 \\
& S=2,04757 \\
& { }_{3} C p=7,77103
\end{aligned}
$$

Karena nilai $C p>1$, maka proses kapabel. Jadi dapat dikatakan bahwa kondisi kemampuan proses yang terjadi pada faktor 2 yang meliputi karakteristik kualitas kekeruhan, $\mathrm{Pb}$ dan $\mathrm{Fe}$ berjalan dengan baik.

\section{KESIMPULAN}

Berdasarkan hasil penelitian yang telah dilakukan, maka dapat disimpulkan :

1. Dari 12 variabel kualitas air PDAM Gresik yang diamati, hanya enam variabel yaitu TDS, Kesadahan, Kekeruhan, Timbal $(P b)$, Besi $(F e)$ dan Suhu yang berpengaruh terhadap kualitas air di PDAM Gresik.

2. Untuk variabel TDS, Kesadahan dan Suhu adalah variabel kualitas air produksi PDAM Gresik yang belum terkendali secara statistik. 
Saran yang dapat disampaikan adalah pihak PDAM Gresik sebaiknya menggunakan peta kendali Hotelling dan peta kendali $\bar{x}$ dan $S$ sehingga memudahkan melihat keadaan suatu variabel pada saat tidak terkendali dan tindakan penanganan dapat lebih cepat dilakukan.

\section{Pustaka}

[1] Johnson, R.A. and Wichern, D.W., (1988), Applied Multivariate Statistical Analysis Third Edition, Prentice Hall, Englewood Cliffts, New Jersey.

[2] Montgomery, D.C., (1995), Pengendalian Kualitas Statistik, Gajah Mada University Press, Yogyakarta.

[3] Samuel K., Johnson N.L., (1993), Process Capability Indices First Edition, Chapman and Hall, London.

[4] Sharma, S., (1996), Applied Multivariate Techniques, John Wiley \& Sons Inc, New York.

[5] Yudhawati, U., (2001), Analisis Multivariate Pada Proses Pengolahan Air Minum Instalansi Penjernihan II di PDAM Kotamadya Surabaya, Institut Teknologi Sepuluh Nopember, Surabaya 